\title{
Correlation between congenital bicuspid aortic valve morphology with thoracic aortic dimensions - a retrospective analysis with cardiovascular magnetic resonance
}

\author{
Lay Koon Tan ${ }^{1,3^{*}}$, Beatrice Bonello', Yumi Shiina ${ }^{1}$, Raad H Mohiaddin ${ }^{1,2}$ \\ From 16th Annual SCMR Scientific Sessions \\ San Francisco, CA, USA. 31 January - 3 February 2013
}

\section{Background}

Congenital bicuspid aortic valve (BAV) is the commonest inherited cardiac defect that is often associated with a medley of other cardiovascular anomaly, the most frequent being aortic dilatation which may be a consequent of an interplay between genetic and hemodynamic factors. This retrospective study aims to find a correlation between BAV valve morphology with thoracic aortic dimension with cardiovascular magenetic resonance imaging (CMR).

\section{Methods}

A retrospective analysis of the aortic valve and aortic (Ao) dimension was made of 149 patients aged between 6 and 77 years (mean age $43 \pm 17,102$ males and 47 females) with BAV who underwent CMR study. BAV patients with associated coarctation or valvular dysfunction were excluded. Images were acquired with either a
Siemens Avanto or Sonata 1.5T scanner in orthogonal planes. Aortic maximal intraluminal dimensions in end diastole were measured at the annulus, sinuses, sino-tubular junction, mid ascending aorta, arch and proximal descending aorta. These measurements were indexed according to body surface area (BSA). BAV valve morphology were characterised in cross-sectional steadystate free precession (SSFP) cine images and grouped according to the presence or absence of a raphe.

\section{Results}

Of the valve morphology, majority of patients (59.7\%) had a raphe, almost always seen between the fused right and left cusps (89\%). The indexed aortic root and ascending aortic dimensions were found to be smaller in patients with remnant raphe BAV as compared with those without a raphe ('pure' BAV). There was a trend towards smaller

Table 1 Median Indexed Aortic Dimension in BAV with raphe and Pure BAV patients

\begin{tabular}{cccc}
\hline & BAV with raphe Median $(95 \% \mathrm{Cl})(\mathrm{mm} / \mathrm{m} 2)$ & Pure BAV Median $(95 \% \mathrm{Cl})(\mathrm{mm} / \mathrm{m} 2)$ & Significance $(\mathrm{p}$ value $)$ \\
\hline Aortic Annulus & $14.0(13.7-14.5)$ & $14.9(14.3-15.5)$ & 0.007 \\
Aortic Sinus & $18.2(17.7-18.9)$ & $20.7(19.9-21.7)$ & 0.0001 \\
Sinotubular Junction & $14.2(13.7-14.6)$ & $16.1(14.5-17)$ & 0.004 \\
Mid Ascending Aorta & $17.8(17.2-18.6)$ & $19.2(18.3-20.4)$ & 0.03 \\
Proximal Arch & $13.5(13-14.3)$ & $14.0(13.2-14.9)$ & 0.07 \\
Mid Arch & $11.0(10.7-11.5)$ & $11.3(10.6-11.9)$ & 0.7 \\
Proximal Descending Aorta & $10.6(10.1-10.9)$ & $10.5(10-11.1)$ & 0.9 \\
\hline
\end{tabular}

$\mathrm{Cl}$ - confidence interval

${ }^{1}$ CMR, Royal Brompton Hospital, London, UK

Full list of author information is available at the end of the article

(c) 2013 Tan et al; licensee BioMed Central Ltd. This is an Open Access article distributed under the terms of the Creative Commons 
indexed proximal aortic arch dimensions in BAV patients with valvular raphe although this did not reach statistical significance $(\mathrm{p}=0.07)$. There were no difference in indexed aortic arch and proximal descending aortic dimension between the 2 groups as shown in the table below:

\section{Conclusions}

Majority of BAV patients have a remnant raphe, commonly between the fused right and left cusps. These patients were also found to have smaller indexed aortic root and ascending aortic dimensions compared with those with 'pure' BAV which may indicate an inherent difference in biologic aortic structure.

\section{Funding}

No funding.

\section{Author details}

${ }^{1}$ CMR, Royal Brompton Hospital, London, UK. ${ }^{2}$ National Heart and Lung Institute, Imperial College, London, UK. ${ }^{3}$ Cardiology, National Heart Institute, Kuala Lumpur, Malaysia.

Published: 30 January 2013

- Convenient online submission

- Thorough peer review

- No space constraints or color figure charges

- Immediate publication on acceptance

- Inclusion in PubMed, CAS, Scopus and Google Scholar

- Research which is freely available for redistribution 